Rev. Psicol. (Arequipa. Univ. Catól. San Pablo) / Año 2020 / Vol 10 / N 1 / pp. 81-98

ISSN 2306-0565 versión impresa / ISSN 2311-7397 versión on line

(c) $\$ \bigoplus$ Esta obra está bajo una Licencia Creative Commons

Atribución 4.o Internacional (BY-NC-ND)

\title{
GUÍA BREVE Y ACTUALIZADA PARA ANALIZAR LA PERSONALIDAD DESDE EL CONDUCTISMO
}

\section{A BRIEF AND UPDATED GUIDE TO THE ANALYSIS OF PERSONALITY FROM THE BEHAVIORIST PERSPECTIVE}

\author{
William Montgomery Urday \\ Universidad Nacional Mayor de San Marcos, Lima, Perú
}

\begin{abstract}
Resumen
En el presente artículo se lleva a cabo una revisión de las teorías conductistas a manera breve y actualizada, valorando el constructo de "personalidad" como imprescindible. Se sostiene que dichas teorías son poco difundidas, por lo cual su desconocimiento es notorio tanto en estudiantes como en profesionales interesados en el tema de la personalidad. En tal sentido, después de hacer un recorrido histórico del tratamiento del problema de la personalidad en el conductismo, se abordan sus variantes contemporáneas: el sociocognitivismo, el conductismo psicológico, el interconductismo y la teoría de marcos relacionales. Finalmente se culmina con una breve apreciación comparativa de aquello que aportan todas ellas.
\end{abstract}

Palabras clave: Personalidad, teoría, aprendizaje social, sociocognitivismo, conductismo psicológico, interconductismo, teoría de marcos relacionales.

\begin{abstract}
This article provides a brief and updated review of behavioral theories, while valuing the construct of "personality" as essential. It is argued that these theories are poorly disseminated, resulting in the well-known ignorance of the behavioral perspective among students and professionals interested in the subject of personality. After making a historical tour of the treatment of the problem of personality in behaviorism, its contemporary variants are discussed: sociocognitivism, psychological behaviorism, interconductism and the theory
\end{abstract}


of relational frameworks. Finally, it ends with a brief comparative appreciation of what they all contribute.

Key words: Personality, theory, social learning, sociocognitivism, psychological behaviorism, interbehaviorism, relational framework theory.

Una revisión de los principales textos anglosajones e iberoamericanos sobre psicología de la personalidad (Pervin, y John, 1970/200o; Fadiman y Frager, 1979/2010; Brodyy Ehrlichman, 1998/2000; Polaino-Lorente, Cabanyes y Del Pozo, 2003; Larsen y Buss, 2003/2005; Cueli, Reidl, Martí, Lartigue y Michaca, 20o8; Cervoney Pervin, 2004/2009; Bermúdez, Pérez-García, Ruiz, Sanjuán y Rueda, 2011; Carver y Scheier, 2012/2014; Feist, Feist y Roberts, 2013/2014; Di Caprio, 1974/2018), deja en claro que su consideración del papel que juegan las variantes conductuales en este sector del conocimiento psicológico es muy limitada. La mayoría solo reseña la variante skinneriana, $y$, a veces, ni eso. A menudo otros enfoques acerca de la personalidad vinculados al paradigma conductual, como son los de Dollard y Miller (1950/1981) o Eysenck (1967/1978), son encasillados respectivamente como "aprendizaje social" y “factorialismo". A Rotter (1954/1965) y a Bandura y Walters (1963/1977), por su parte, se les incluye entre las variantes “cognitivas” sin ligarlas por ningún lado con su parte conductual.

Desde luego que esta tendencia no hace más que reproducir el prejuicio histórico típico de la comunidad psicológica en relación al universo conductual: conductismo ("ortodoxo") es equivalente a Skinner, y Skinner es equivalente a "organismo vacío”.
Por lo tanto, puesto que según esto la de Skinner es una especie de "anti-teoría de la personalidad" por su ambientalismo, es impensableque desde semejante postura pueda salir algo de valor en dicho rubro. Así, con excepción de Cloninger (2002/2003), quien incluye también a otro autor conductista de distinta composición (Staats, 1996/1997) en su recuento de teorías (siendo sintomático que su libro - el de Cloninger - no haya sido reeditado hasta ahora), nadie más aparece representando al paradigma de la ciencia del comportamiento en la personalidad, ni siquiera el temprano análisis sistemático de Lundin (1961). ¡En algún caso, inclusive, se atribuyen las ideas de ciertos autores neoconductistas (Mowrer, Miller) al psicoanálisis! (ver Lester, 2019, p. 29; Cloninger, 2002/2003; p. 312)1. Se ignoran, asimismo, las contribuciones de enfoques y autores conductistas de campo y contextuales recientes, como las de Ribes y Sánchez (1990), Ribes (2009, 2018), Kohlenberg y Tsai, (1995/2001); Luciano, Gómez y Valdivia (2002); Pérez-Âlvarez y García-Montes (2004).

Para el estudiante de psicología interesado en el tema debe ser muy complicado enterarse de cuál es el estado de la cuestión en referencia, dada la oquedad de información sobre ella. No sorprende, pues, que cuando se le pregunte por el estudio de la personalidad a partir del 
conductismo, pueda responder estereotipadamente con un "no sé", o peor, con una frase como la de que "para el conductismo no existe la personalidad". Este desconocimiento es notorio incluso en profesionales que pretenden estar especializados en teorías de la personalidad (ver por ejemplo el trabajo de Montaño; Palacios y Gantiva, 2009). Por el contrario, como señala Phelps (2015), al revés de la opinión comúnmente generalizada que hace que las posturas de los autores comportamentales sobre la personalidad sean raramente presentadas a fondo (asumiendo que ellos han dejado de lado ese tema en sus escritos); desde los inicios del conductismo los teóricos de esa corriente le han dedicado considerable atención.

En mérito a lo manifestado, en las siguientes secciones se emprende una reseña general de las teorías conductistas a manera de "guía breve" y actualizada, en el entendido de que el constructo de "personalidad", al margen de algunos errores históricos conceptuales que aún perviven respecto a su definición y contenidos tradicionales, es útil e imprescindible para ubicar un productivo marco de referencia evaluativo y una eficaz práctica concomitante (Santacreu, Hernández, Adarraga y Márquez, 2002; Santacreu, 2005; Kantor \& Smith, 1975/2015).

El plan de exposición sobre conductismo y personalidad comprende los siguientes apartados: a) primeros pasos y b) perspectivas contemporáneas. Se concluye con la mención de algunas derivaciones prácticas acerca de las variantes reseñadas y un comentario final.

\section{Conductismo y personalidad: primeros pasos}

En el capítulo XII de su obra El Conductismo, Watson (1924/1945) dice: «La personalidad es la suma de las actividades factibles de descubrirse mediante una observación real de la conducta, suficientemente larga como para que pueda suministrarnos una información segura. En otros términos, la personalidad no es sino el producto final de nuestros sistemas de hábitos» (p. 308). Por lo tanto, estos son identificables a través de corrientes consistentes y estables de actividades recreativas, gestuales, interpersonales, de prácticas morales, sociales, aritméticas; e incluso de reacciones emocionales. Sin duda, este es el punto de partida de la cuestión tal y como se concibe conductualmente.

No puede dejar de señalarse que el sociólogo G. H. Mead (1935/1973) hace, en su momento, desde una postura que él llama "conductismo social", una serie de observaciones y puntualizaciones a la concepción watsoniana. La personalidad para Mead no es un elemento aislado ni independiente, es un producto social porque su desarrollo involucra la precedencia de un grupo social y la pertenencia a éste. Es en aquel marco ambiental que el individuo humano se implica en las actitudes de su comunidad con respecto a todos los asuntos que competen a su vida cotidiana, y, de acuerdo con ellas, 
erige su mundo de significados y dirige su propia conducta.

\section{Las variantes de aprendizaje social}

Los primeros autores neoconductistas, ligados al modelo mediacional de Clark Hull y el grupo de la Universidad de Yale, hacen camino en base a dicho tronco. Hull (1943) declara, refiriéndose a su teoría:

La presente aproximación no pretende negar la realidad molar de que los actos intencionales (como opuestos a los movimientos), de la inteligencia, de la intuición, de la representación de fines o de objetivos, o de intentos, o de evaluaciones, por el contrario, se insiste aquí en lo genuino de estas formas de conducta. Espero demostrar, sin embargo, en último término, la validez lógica de tales conceptos deduciéndolos como principios secundarios de principios objetivos más elementales y primarios. Una vez hecha la derivación, no sólo los comprenderemos mejor, sino que seremos capaces de usarlos con efectividad más precisa. (pp. 25-26)

Algunos de los que tratan explícitamente el tema de la personalidad basados en semejantes principios son Dollard y Miller (1950/1984), Sears (1951) y Mowrer (1950); en lo que se ha llamado "primeras teorías de aprendizaje social", cuyo fundamento gira en torno a tres tipos de influencia: por un lado los mecanismos del condicionamiento respondiente e instrumental; por otro las respuestas mediadoras (verbales o fisiológicas) que evocan señales y respuestas instrumentales internas; $y$ por último las variables de impulso, de señal, y de refuerzo como reducción del impulso que acompañan la interacción del individuo con eventos externos.

El objetivo central de este enfoque en su conjunto consiste en procurar inicialmente la adecuación de ciertos principios psicoanalíticos a una conceptuación de aprendizaje por condicionamiento (eslabones estímulo-respuesta) más objetiva y experimental, pero dentro de un marco antropológico social. Por ejemplo, el "inconsciente" freudiano podría ser explicado por estímulos internos (impulsos), externos (señales) y reacciones que se aprendieron en una etapa del desarrollo previa a la aparición del habla del sujeto, siendo, en consecuencia, de poca claridad conceptual para él. Otra explicación no incompatible con la anterior sería la de respuestas anticipatorias de "no pensar" en ciertas cosas "agradables" o "desagradables", como efecto de impulsos conscientes que se reprimieron por temor al castigo moralista del entorno sociocultural. Los episodios clave para este tipo de aprendizajes se hallan en las etapas del desarrollo que enfatizan la alimentación del lactante, el control de los esfínteres, la impronta sexual y el logro del control de la agresión.

Una "segunda ola" de aprendizaje social representada por Rotter (1954/1964) y Bandura y Walters (1963/1977), irrumpe luego, incorporando algunas de las aserciones de sus predecesores y ampliando su marco de acción así como el papel de las variables cognitivas. 
Rotter, en particular, considera que la conducta del individuo es direccional, esto es, teleológicamente influida por sus objetivos; lo cual pone en primer lugar la capacidad de preveer los hechos y las expectativas por conseguir tales metas de acuerdo con el significado que se les atribuya. En este proceso están implicados cuatro factores además de las expectativas: el potencial de conducta (probabilidad de ocurrencia), el valor de refuerzo (preferencia por algo), la situación psicológica (señales del entorno percibidas en un momento dado), y la afectación de otras conductas potenciales en la misma situación. Posteriormente, Rotter añade a su teoría conceptos complementarios en la categoría de "expectativas generalizadas", como las de locus de control (grado de expectativa sobre cuánto puede influir sobre los acontecimientos la propia acción personal), y de confianza interpersonal (grado de expectativa sobre cuánto puede confiar una persona en otra).

Bandura y Walters (1963/1977) relievan el aprendizaje por observación (condicionamiento vicario), específicamente en su cualidad imitativa y modeladora, por lo que estudian de manera detallada cómo se adquiere la conducta a través de esos mecanismos simbólicos. La idea es que los sujetos observadores de actos realizados por otros individuos (modelos), en determinadas situaciones tienden a imitarlos en circunstancias parecidas. Esto puede ocurrir en presencia directa o a través de imágenes. Así, los modelos pueden evocar (o desinhibir) en sus imitadores conductas ya existentes, conductas socialmente deseables o indeseables, e incluso desviadas. El condicionamiento vicario puede ser de tipo instrumental cuando se aprenden conductas operantes; $\mathrm{o}$ respondiente cuando se aprenden respuestas emocionales. Por tanto, mediante esos procesos se pueden adquirir, por ejemplo, diversas habilidades de ejecución o reacciones de temor o ira.

\section{La teoría trifactorial de Eysenck}

Simultáneamente al auge de las anteriores propuestas de aprendizaje social, también se desarrolla el muy prolífico enfoque de Eysenck (1967/1978), que, aunque en su matriz igualmente proviene de la teoría de Hull, se halla mucho más dedicado a analizar los fundamentos biológicos del comportamiento. Su tesis principal radica en que la conducta se organiza básicamente en función a tendencias temperamentales (por tanto genéticas) que dan forma a respuestas elementales, aquellas a los hábitos, y estos agrupados correlacionalmente, conforman características destacadas de la personalidad (rasgos) que en última instancia se erigen en estructuras factoriales llamadas "tipos". El proceso comienza de manera muy elemental y se va complejizando a través de sucesivas organizaciones que culminan en tres superfactores bipolares: a) extraversión-introversión, o grado de sociabilidad actividad e impulsividad; b) estabilidad-neuroticismo, o grado de reacción ante situaciones de emergencia; y c) superyó-psicoticismo, o grado de expresión de la emoción.

El estudio de los tres superfactores y su respectiva evaluación en cada individuo 
permite, según Eysenck, predecir la conducta con cierta fiabilidad, en tanto ubica tendencias de respuesta instrumental o respondiente en situaciones diferenciales. Por ejemplo, la reacción de un sujeto introvertido ante estímulos perturbadores (bulliciosos, recargados, exigentes, de dificultad intensa, etcétera), es distinta en gradación y consecuencias a la que puede ofrecer un extrovertido, independientemente de su historia de aprendizaje sociocultural.

\section{El conductismo radical}

Otro conductismo emergente por entonces, es el conductismo radical de B. F. Skinner (1974/1977; 1986/1991), para quien la personalidad y el yo son solo un locus donde convergen aspectos biológicos y sociales. No es, en este sentido, un constructo válido como agente iniciador del comportamiento, pues depende de las contingencias ambientales (antes-durante-después) que determinan la conducta a través de sus consecuencias gratificantes y no gratificantes (conducta operante). El énfasis que Skinner le da a las contingencias no impide que considere procesos de autocontrol personal, gracias a la facultad dada por la conducta verbal para permitir autorregular, autosondear, autorreforzar y autoinstigar el propio comportamiento, entre otras posibilidades. En esta línea, para Harzem (1984), el análisis conductual skinneriano sería capaz de resolver cuestiones tales como esclarecer aquellos tipos de experiencia con efectos transitorios o duraderos sobre el individuo, o de qué manera las exposiciones previas a ciertas contingencias determinan patrones de comportamiento actuales, y si aquellos se pueden cambiar y en base a qué procedimientos.

Finalmente, desde una convergencia inspirada por los enfoques hulliano y skinneriano, Lundin (1961) propone un enfoque experimental para el estudio de la personalidad como algo observable, medible, predecible y controlable, ocupándose de ventilar problemas de motivación, control aversivo, frustración y conflicto, amén de otras cuestiones aplicadas.

\section{Perspectivas contemporáneas}

\section{Sociocognitivismo: \\ El individuo como agente}

En la segunda parte de su trayectoria, influenciado por la tendencia de la psicología en general -y especialmente conductual-a "empaparse de cognitivismo", Bandura (1986/1987) extiende su versión del aprendizaje social enfatizando cada vez más el papel del individuo como agente autorregulador de sí mismo, incluyendo procesos tales como la atención y la retención, el pensamiento, la representación simbólica en la memoria, la retroalimentación experiencial y las estraegias. Gracias a ellos asume que el sujeto tiene capacidad para percibir y para prever acontecimientos, pues las consecuencias de sus respuestas le retroinforman, sirviéndole de guía para desempeños futuros. Así, puede afirmarse que las personas 
evalúan constantemente sus actos y capacidades, surgiendo el concepto clave de autoeficacia percibida, que se plasma a través de los juicios que un individuo hace respecto a sus posibilidades potenciales de organizar y poner en función su conducta, a fin de rendir según desea en una situación específica (Figura 1).

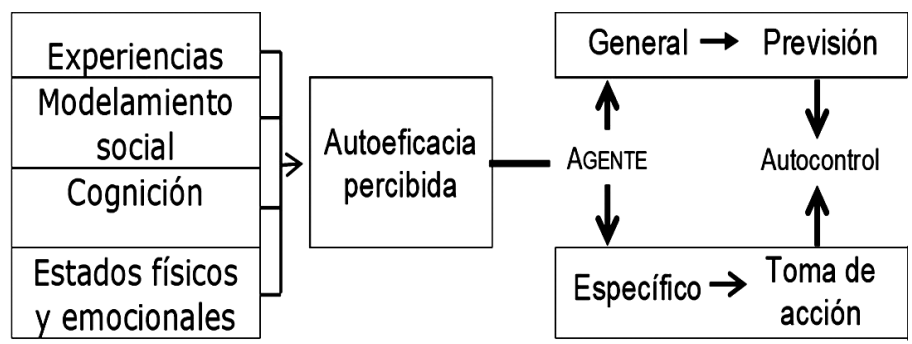

Figura 1. Esquema del enfoque de Bandura, que considera la autoeficacia clave para configurar un individuo como agente activo y autocontrolador

Con estos reajustes, la teoría de Bandura pasa a llamarse "sociocognitiva" y entra a formar parte del bloque de los enfoques "conductual-cognitivos", con la particularidad de que plantea un marco general del funcionamiento psicológico que se refleja en tres tipos de relaciones causales interdependientes (reciprocidad triádica o determinismo recíproco) entre la conducta, la persona y el entorno (ver una reactualización de Bandura, 2011). Los factores conductuales se entienden como sistemas de respuesta gobernados por principios de aprendizaje; los factores de la persona aluden a los procesos cognitivos; y los factores del entorno se refieren al ambiente que engloba todo aquello.

\section{Conductismo psicológico: \\ Los repertorios básicos}

Staats $(1979,1997)$ señala que lo que se rotula como "personalidad" es una construcción conceptual unitaria conformada por varias constelaciones de respuestas interrelacionadas entre sí, aprendidas desde la infancia. A estas constelaciones sistémicas las llama repertorios básicos conductuales (RBC), que son tanto aprendidos ("variable dependiente") como propiciadores de más aprendizaje ("variable independiente"), mediante varios tipos de interacción conducta-conducta (una conducta determina otra); conducta-conducta indirecta (repertorios generales disponen condiciones para adquirir o emitir conductas); e interacción conducta-ambiente-conducta (la persona cambia su entorno y éste ayuda a determinar el comportamiento futuro del mismo sujeto).

En suma, la personalidad (RBC) es producto a la vez de condiciones ambientales históricas y condiciones organísmicas antecedentes $\left(\mathrm{O}_{1}\right)$, pero ya estructurada, determina conductas presentes y futuras, y estados orgánicos particulares $\left(\mathrm{O}_{2}\right)$. Igualmente, influyen sobre ella ciertas condiciones ambientales y orgánicas actuales $\left(\mathrm{O}_{3}\right)$ que modulan respuestas de tipo situacional (Figura 2). 


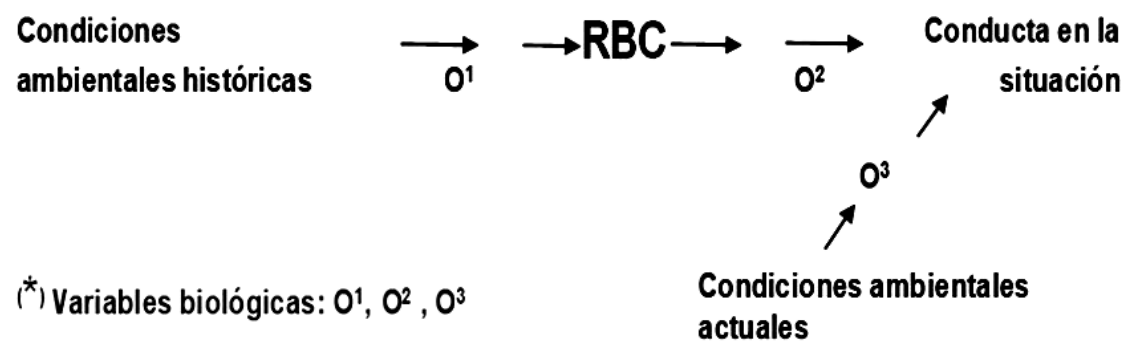

Figura 2. Esquema de la personalidad según Staats (1996/1997, p. 228)

Hay básicamente tres grandes sistemas de RBCs: cognitivo-lingüístico, emotivo-motivacional y motor sensorial, que se relacionan con múltiples experiencias personales. El sistema cognitivo-lingüístico se compone de repertorios de lenguaje y sus propiedades directivas (a través del razonamiento y la planeación) y evocadoras de emoción. El sistema emotivo-motivacional conlleva respuestas emocionales de acercamiento o evitación a diversas particularidades del ambiente. El sistema motor sensorial, a su vez, tiene que ver con los movimientos corporales que operan como destrezas o patrones de acción/ reacción e imitación.

El proceso de aprendizaje de la personalidad es central en este enfoque, $y$, tal como lo concibe Staats, se muestra como un proceso de condicionamiento clásico e instrumental de tres funciones, donde el estímulo incondicionado tiene a la vez propiedades actitudinal, reforzantey directiva (A-R-D). Esta última constituye el acicate para emitir un gran número de respuestas instrumentales de diversa índole y complejidad frente a situaciones también ubérrimas.

\section{El interconductismo: \\ Los estilos interactivos}

Kantor y Smith (1975/2015) hacen hincapié en que los fenómenos psicológicos pueden compararse con un flujo continuo, pero ante la necesidad de tener una unidad de análisis dicho flujo se puede fragmentar en partes, cada una de las cuales es un "segmento conductual" donde interactúa un conjunto de variables organísmicas, estimulares, históricas y situacionales2. Desde esta perspectiva se presenta el problema de analizar la personalidad como un evento de campo interconductual, labor que emprenden Ribes y Sánchez (1990), y Ribes (2009, 2018), connotándola en función a su papel de contacto individual invariante e idiosincrático de interacción con las particularidades de cada campo o sistema contingencial.

Esto es lo que Ribes llama "estilo interactivo", un concepto disposicional de tipo histórico (porque se formó en el devenir del individuo), que implica una ocurrencia singular, consistente y predecible de conducta. Es la actividad 
misma del individuo, tal como es referida adverbialmente por un observador en términos de descripción de la peculiaridad de alguien (sobre su saber, sus gustos o costumbres), y puede ser caracterizada mediante un perfil funcional que grafique su consistencia individual (u opción de ajuste frecuente) frente a diferentes configuraciones experimentales de las dimensiones contingenciales. Estas configuraciones, en la última actualización que Ribes (2018) hace al respecto, son denominadas de "riesgo", "decisión", "ambigüedad", “distracción”, "frustración", "persistencia de logro", "escudriñamiento" y "conflicto" (Figura 3).

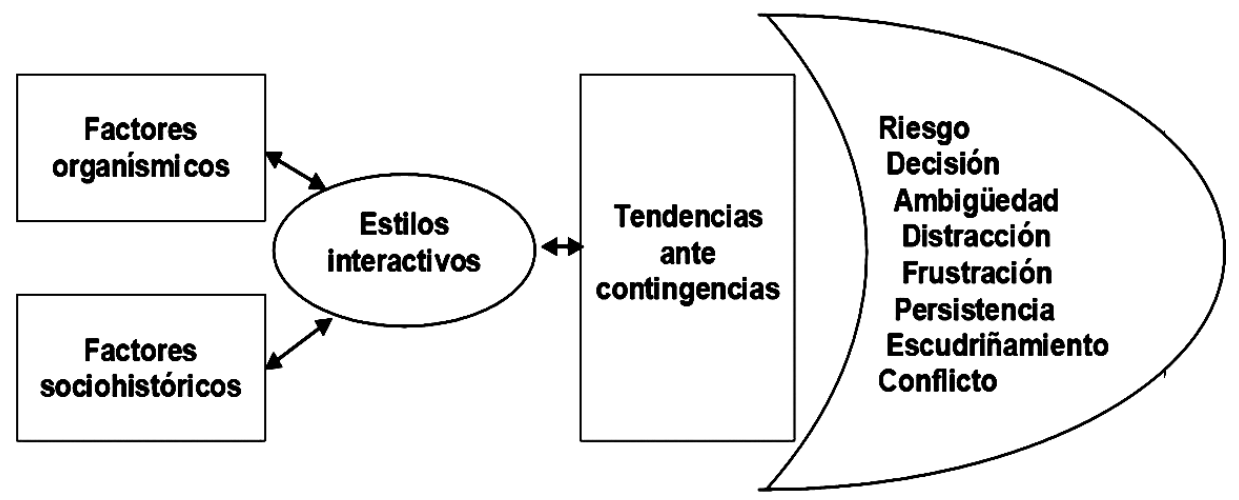

Figura 3. Los estilos interactivos y las variables que hacen contacto funcional con ellos

Dado que sus características técnicas son bastante complicadas, a continuación solo se indica lo principal de cada una, remitiendo a la obra del mismo autor para una explicación detallada (pp. 494 y ss.).

En las contingencias de riesgo la interacción se conforma con base en el número de alternaciones entre dos opciones de respuesta.

En las contingencias de decisión es importante la latencia de respuesta frente a la posibilidad de optar entre dos eventos temporalmente separados.

En las contingencias de ambigüedad se analiza el pase de la opción más ambigua a la menos ambigua, en una situación donde es imposible discriminar propiedades funcionales de los eventos.

En las contingencias de distracción son de notar las respuestas correctas (o su omisión) e incorrectas ante una propiedad funcional o distractora.

En las contingencias de frustración se verifican las repuestas del sujeto durante opciones de bloqueo (impedido o demorado) y no bloqueo, sin información previa.

En las contingencias de persistencia de logro se evalúa la responsividad bajo condiciones de requisito creciente cuando 
las consecuencias del comportamiento se mantienen constantes.

En las contingencias de escudriñamiento se estudia la característica de permanencia e intensidad responsiva en una situación de diversidad cualitativa y cuantitativa de estímulos potenciales que no requieren respuesta.

En las contingencias de conflicto El estilo correspondiente se evalúa en términos de respuestas ante señales competitivas, en relación al tiempo de exposición y a la alternación entre las opciones.

Para finalizar esta parte, hay que decir que los estilos interactivos son autónomos respecto a los procesos de motivación, pero influyen en la adquisición de motivos tanto como de competencias.

\section{Teoría de marco relacional:} Trascendencia del Yo

La "experiencia del yo" es retomada recientemente desde el conductismo radical del siglo XXI por la teoría del marco relacional, siendo las alusiones a la personalidad en su conjunto extremadamente escasas. Inicialmente, Kohlemberg y Tsai (2001) señalan que las autorreferencias verbales bajo control de estímulos relevantes, tales como los "tactos" (rotulaciones) sobre sí mismo, emergen como unidades funcionales independientes en el transcurso del desarrollo humano gracias a un proceso por el cual éstas se transfieren, poco a poco, del lenguaje público utilizado por los padres al lenguaje privado del infante, traduciéndose en la posibilidad de un informe verbal del "yo" y en una relación entre el sí mismo y el ambiente (Figura 4).

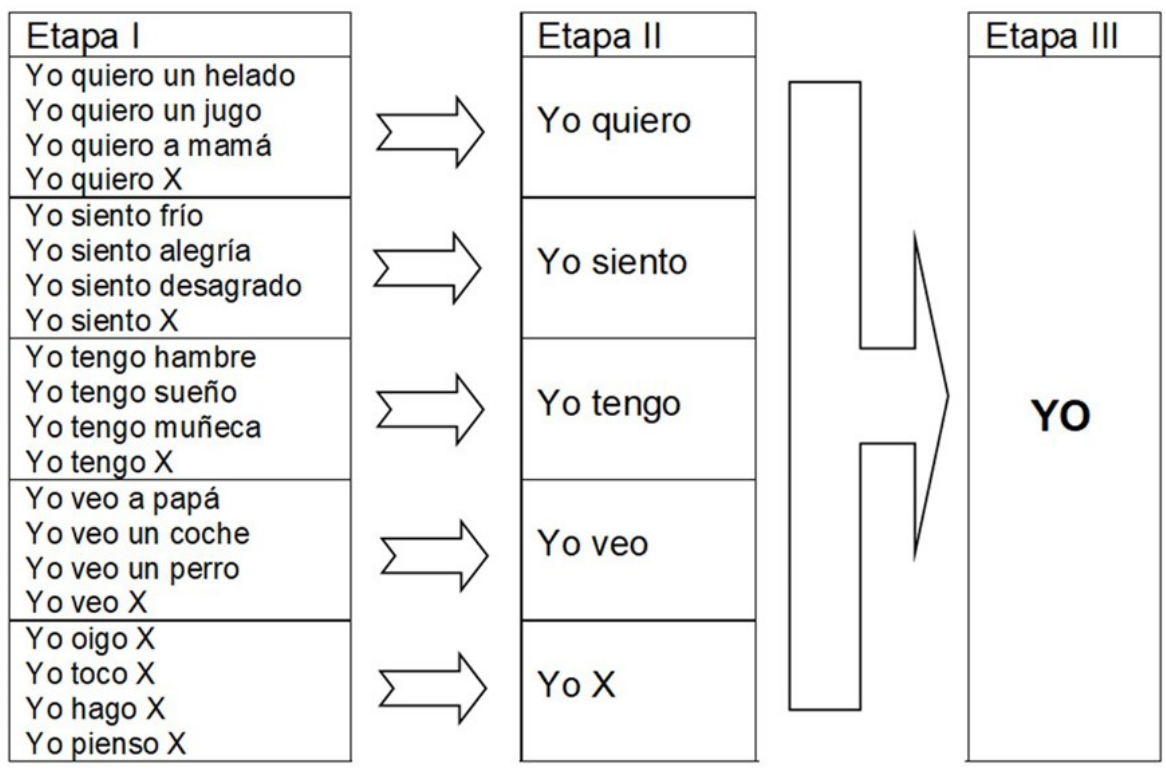

Figura 4. Proceso de moldeamiento progresivo de las autorreferencias que lleva al informe verbal del "Yo" 
A esta génesis del yo se le ha llamado "fenomenológica" desde una perspectiva contextual, porque da cuenta de la experiencia psicológica (o privada) sin salir del marco de la triple contingencia, puesto que la autoexperiencia de ver, sentir y pensar no implica necesariamente tener una representación mental, aunque ser consciente de algo - gracias a los marcos deícticos del lenguaje que permiten la toma de perspectiva ("yo-concepto", "yo-proceso", "yo-contexto")—, pueda inducir al sujeto a pensar o sentir que alberga un "ser interior" dentro de su persona (Martin y Ferro, 2016).

Las cuestiones relativas al intrincado problema de la formación del "yo-conceptualizado", "yo-contexto" y "yo-proceso", son tratadas extensamente por Hayes, Strosahl y Wilson (2012/2014). En breve, el "yo-concepto" (pp. 135 y ss.) tiene su origen en los aprendizajes discriminativos de autorreconocerse en base a categorizaciones socioculturales sobre las diferentes características personales (gustos, carácter, etcétera) del individuo; el "yo-contexto" (pp. 141 y ss.) implica la trascendencia del yo como perspectiva, dada por la continua utilización verbal de comparaciones y otros tipos de conexión en marcos relacionales de distinción de identidades (por ejemplo "yo-tú-otros"), de espacialidad (por ejemplo "acá-allá", "cerca-lejos") y los marcos temporales (por ejemplo "ahora-antes-luego"); y el "yo-proceso" (pp. 338 y ss.) viene a ser el yo "autoconsciente" de la experiencia inmediata o relación con uno mismo en el aquí y el ahora.

\section{Derivaciones prácticas y comentario final}

Es bien sabido que en la psicología clínica hay dos orígenes en la elección de tratamientos psicoterapéuticos: por un lado el seguimiento de una teoría formal acerca de la personalidad en relación con el problema concreto, y por otro la queja del cliente en particular. Así, las fases de creación, construcción, valoración y aplicación de los programas se encuentran guiadas en primer lugar por el modelo teórico que le sirve de referencia al especialista para diseñar sus estrategias profesionales. Sin embargo, hay una tensión existente entre el ejercicio de la profesión "a demanda” versus el ejercicio sistemático regido por principios extraídos de la investigación (Olivares, Maciá, Olivares y Rosa, 2012). Esta tensión se refleja también en los planteamientos de las teorías de la personalidad más recientes, como es notorio al comparar los intereses que rigen a unas y otras, cada una se guía por un marco de referencia propio y evalúa el comportamiento de acuerdo con unidades analíticas diferentes, tal como las que se han señalado en la sección anterior (Tabla 1). 
Tabla 1. Teorías conductistas y conductual-cognitivas recientes de la personalidad, sus marcos referenciales y unidades de análisis

\begin{tabular}{|l|l|l|}
\hline \multicolumn{1}{|c|}{ Enfoque teórico } & \multicolumn{1}{c|}{ Marco de referencia } & \multicolumn{1}{c|}{ Unidad analítica } \\
\hline $\begin{array}{l}\text { Marcos relacionales } \\
\text { Sociocognitivo }\end{array}$ & $\begin{array}{l}\text { Conducta verbal } \\
\text { Reciprocidad triádica } \\
\text { Sistema actitudinal- } \\
\text { reforzante-directivo }\end{array}$ & $\begin{array}{l}\text { Tactos autorreferenciales } \\
\text { Autoeficacia }\end{array}$ \\
Conductismo Psicológico & Repertorio conductual básico \\
Interconductismo & Campo de Interacciones & Estilo interactivo \\
\hline
\end{tabular}

En términos amplios, se pueden juzgar los aportes de los modelos antes reseñados hurgando sobre su capacidad para cumplir con tres requisitos indispensables del quehacer científico-profesional:a) la sistematización y coherencia de sus supuestos; b) la extensión de sus principios a nuevos y más complicados problemas; y c) la efectividad práctica para tratar una amplia gama de conductas no deseables. Queda pendiente la tarea de profundizar sobre estos aspectos en un artículo posterior, por ahora solo basta indicar lo que figura en los tres párrafos que siguen.

Haciendo la evaluación respectiva en base no solo a lo dicho aquí, sino a una revisión mayor (por ejemplo Santacreu et al., 2002; Santacreu, 2005; Montgomery, 2005, 2017), en opinión falible del autor de este ensayo parece quedar claro que los enfoques teóricos con mayor preocupación por sistematizar y hacer coherentes sus supuestos son, en primer lugar, el interconductismo, y en segundo el conductismo psicológico.

En cuanto a la extensión de sus principios a nuevos y más complicados problemas, la teoría de marcos relacionales (que desciende del conductismo radical) sería la que se lleva la palma, procurando abordar complejas dificultades existenciales (véase McHugh, Stewart \& Almada, 2019). No es que este enfoque descuide sensu stricto los rubros de sistematización y coherencia (como consta en De Houwer, Barnes-Holmes \& Barnes-Holmes, 2016), pero, definitivamente, estos quedan en segundo lugar respecto a su afán innovador sobre temas más "profundos” del "yo”.

Referente a la efectividad práctica para tratar una amplia gama de conductas clínicamente no deseables, tanto el enfoque sociocognitivista de Bandura como el del aprendizaje social de segunda ola, y el de Staats, podrían considerarse (por el momento) más potentes y seguros, en la medida que propenden a utilizar todo el arsenal de técnicas conductuales-cognitivas disponibles para cumplir con las tareas aplicativas (Olivares, Maciá, Rosa y Olivares, 2014).

La dinámica de la personalidad, como la llama Cloninger (2002/2003), aludiendo los mecanismos por los cuales ésta se expresa, necesita de todas maneras una teoría que la explique. Ese es el desafío de 
la ciencia del comportamiento, y parece en el rubro de la psicología de la personaque se viene cumpliendo con él a despecho lidad. Vale, pues, la difusión al máximo de la falta de popularidad de sus enfoques de sus propuestas tal como aquí se ha en el mundoacadémico, y particularmente procurado emprender. 


\section{Referencias}

Bandura, A. (1986/1987). Pensamiento y acción. Barcelona: Martínez Roca.

Bandura, A. (2011). Social cognitive theory. In P. A. M. van Lange, A. W. Kruglanski \& E. T. Higgins (Eds.). Handbook of social psychological theories (pp. 349-373). Londres: Sage.

Bandura, A., \& Walters, R. (1963/1977). Aprendizaje social y desarrollo de la personalidad. Madrid: Alianza.

Bermúdez J., Pérez-García, A.M., Ruiz J.A., Sanjuán, P., \& Rueda, B. (2011). Psicología de la personalidad. Madrid: UNED.

Brody, N., \& Ehrlichman, H. (1998/200o). Psicología de la personalidad. Madrid: Prentice-Hall.

Carver, Ch. S., \& Scheier, M. F. (2012/2014). Teorías de la personalidad. México: Pearson.

Cervone, D., \& Pervin, L.A. (2004/2009). Personalidad: Teoría e investigación. México: El Manual Moderno.

Cloninger, S. C. (2002/2003). Teorías de la personalidad. México: Pearson Educación.

Colom-Marañon, R. (2012). Psicología de las diferencias individuales. Madrid: Pirámide.

Cueli, J., Reidl, L., Martí, C., Lartigue, T., \& Michaca, P. (2008). Teorías de la personalidad. México: Trillas.

De Houwer, J., Barnes-Holmes, Y., \& Barnes-Holmes, D. (2016). Riding the waves: A functional-cognitive perspective on the relations among behaviour therapy, cognitive behaviour therapy and acceptance and commitment therapy. International Journal of Psychology, 51(1), 40-44.

Di Caprio, N. S. (1974/2018). Teorías de la personalidad. México: McGraw-Hill Interamericana.

Dollard, J., \& Miller, N. (1950/1981). Personalidad y psicoterapia. Bilbao: Descleé de Brouwer. 
Eysenck, H. J. (1967/1978). Fundamentos biológicos de la personalidad. Barcelona: Fontanella.

Fadiman, J., \& Frager, R. (1979/2010). Teorías de la personalidad. México: Alfaomega.

Feist, J., Feist, G. J., \& Roberts, T.A. (2013/2014). Teorías de la personalidad. México: McGraw-Hill Interamericana.

Freixa, E. (2003). El conocimiento de sí mismo desde la óptica conductista. Psicothema, $15(1), 1-15$.

Harzem, P. (1984). Experimental analysis of individual differences and personality. Journal of the Experimental Analysis of Behavior, 42(3), 385-395.

Hayes, S. C., Strosahl, K., \& Wilson, K. G. (2012/2014). Terapia de aceptación y compromiso. proceso y práctica del cambio consciente. Bilbao Desclée de Brouwer.

Hull, C. (1943). Principles of behavior. N.Y.: Appleton Century Co.

Kantor, J. R., \& Smith, (1975/2015). La ciencia de la psicología. Guadalajara: Universidad de Guadalajara.

Kohlenberg, B. S. (2013). Functional analitic psychotherapy and the use of self. En M. Baldwin (Ed.). The use of self on therapy (pp. 128-140). NY: Routledge.

Kohlenberg, R., \& Tsai, M. (1995/2001). Hablo, luego existo: una aproximación conductual para entender los problemas del yo. Escritos de Psicología, 5, 58-62.

Larsen, R., \& Buss, D. (2003/2005). Psicología de la personalidad. Dominios del conocimiento sobre la naturaleza humana. México: Mc Graw Hill.

Lester, D. (2019). Theories of personality: A system approach. NY: Routledge. Orog.

Luciano, C. M., Gómez, I., \& Valdivia, S. (2002). Consideraciones acerca del desarrollo de la personalidad desde un marco funcional-contextual. International Journal of Psychology and Psychological Therapy, 2(2), 173-197.

Lundin, R. W. (1961). Personality: An experimental approach. New York: MacMillan.

Martin, F., \& Ferro, R. (2016). Building the Self. A Contextual Approach. Psychology, Society, E Education, 8(2), 149-156. 
McHugh, L., Stewart, I., \& Almada, P. (2019). A Contextual Behavioral Guide to the Self: Theory and Practice. Reno: Context Press.

Mead, G. H. (1935/1973). Espíritu. Persona y sociedad. Buenos Aires: Paidós.

Montaño, M., Palacios, J., \& Gantiva, C. (2009). Teorías de la personalidad. Un análisis histórico del concepto y su medición. Psychologia. Avances de la Disciplina, 3(2), 81-10.

Montgomery, W. (2005). Las teorías conductistas de la personalidad y sus correlatos terapéuticos. En El quehacer conductista, hoy (pp. 137-119). Lima: Ediciones de la Revista Peruana de Filosofía Aplicada.

Montgomery, W. (2017). La unidad analítica de la personalidad: ¿Repertorios conductuales básicos o estilos interactivos? Interacciones, 3, 151-159.

Mowrer, O. H. (1950). Learning theory and personality dynamics. Selected papers. N.Y.: Ronald Press.

Olivares, J., Maciá, D., Olivares, P. J., \& Rosa, A. I. (2012). El ejercicio de la psicología aplicada. Madrid: Pirámide.

Olivares, J., Maciá, D., Rosa, A. I., \& Olivares, P. J. (2014). Intervención psicológica: Estrategias, técnicas y tratamientos. Madrid: Pirámide.

Pérez-Álvarez, M. y García-Montes, J.M. (2004). Personality as a work of art. New Ideas in Psychology, 22, 157-173.

Pervin, L. A., \& John, O. P. (1970/200o). Personalidad: Teoría e investigación. México: El Manual Moderno.

Phelps, B. J. (2015). Behavioral perspectives on personality and self. The Psychological Record, 65(3), 557-566.

Polaino-Lorente, A., Cabanyes, J., \& Del Pozo, A. (2003). Fundamentos de psicología de la personalidad. Madrid: Rialp.

Ribes, E., \& Sánchez, S. (1990). El problema de las diferencias individuales: un análisis conceptual de la personalidad. En E. Ribes (Ed.), Problemas conceptuales en el análisis del comportamiento humano (pp. 79-98). México: Trillas. 
Ribes, E. (2009). La personalidad como organización de los estilos interactivos. Revista Mexicana de Psicología, 26(2), 145-161.

Ribes, E. (2018). El estudio científico de la conducta individual. Una introducción a la teoría de la psicología. México: El Manual Moderno.

Rotter, J. B. (1954/1964). Psicología clínica. México: UTEHA.

Santacreu, J. (2005). La síntesis de la historia de aprendizaje: Perspectiva conductual sobre la personalidad, Acta Comportamentalia, 13(1), 53-66.

Santacreu, J., Hernández, J. M., Adarraga, P., \& Márquez, M. O. (2002). La personalidad en el marco de una teoría del comportamiento humano. Madrid: Pirámide.

Schultz, D. P., \& Schultz, S. E. (2010). Teorías de la personalidad. México: Cengage Learning.

Sears, R. R. (1951). A theoretical framework for personality and social behavior. American Psychologist, 6(9), 476-482.

Skinner, B. F. (1991). El yo como punto de partida. En El análisis de la conducta: Una visión retrospectiva. (pp. 45-55). México: LIMUSA.

Staats, A. W. (1996/1997). Conducta y personalidad. Bilbao: Descleé de Brouwer.

Watson, J. B. (1924/1945). El conductismo. Buenos Aires: Paidós. 


\section{Notas}

1 Es verdad que en la época de Mowrer todavía existía un nexo informal entre psicoanálisis y neoconductismo a partir de la reinterpretación que Hull y otros teóricos del aprendizaje hicieron de ciertas tesis freudianas, pero pasar de allí a afirmar que uno de los más destacados expositores neoconductuales anclaba en raíces psicoanalíticas (o fungía de simple "modificador de ideas psicoanalíticas") resulta tan excesivo como caracterizar la teoría de Dollard y Miller como una “teoría psicoanalítica del aprendizaje”. El hecho de que Mowrer, en sus juveniles depresiones, acudiera a tratamiento psicodinámico, y de que el sociólogo Dollard, colaborador de Neal Miller, tuviera real inclinación en ese sentido, no parece justificar las etiquetas mencionadas.

2 El segmento conductual también puede llamarse "sistema contingencial".

Recibido: 8 de octubre de 2019

Aceptado: 6 de enero de 2020 